\title{
RESENHAS|REVIEWS
}

AXELROD, Robert. The Evolution of Cooperation. Nova Iorque: Basic Books, 2006, p. 124141

\section{THE EVOLUTION OF COOPERATION}

CHAPTER 7 - HOW TO PROMOTE COOPERATION

Bruna Faria ${ }^{1}$

Como citar: FARIA, Bruna. Chapter 7: How to promote cooperation. Em: AXELROD, Robert. The Evolution of Cooperation. Nova Iorque: Basic Books, 2006, p. 124-141. Scientia Iuris, Londrina, v. 25, n. 2, p. 208-210, jul. 2021. DOI: 10.5433/2178-8189.2018v22n2p208. ISSN: 2178-8189.

Resumo: Robert Axelrod em seu livro “The Evolution of Cooperation”, em português, "A Evolução da Cooperação", analisa o desenvolvimento da cooperação em jogos de soma não zero, como o Dilema do Prisioneiro. Em si, a sua contribuição não se restringe, unicamente, à matemática e torneios de programas de computadores, podendo ser aplicada e examinada em relações internacionais, microbiologia e até ao Direito. Em razão da densidade da obra, faz-se um recorte no sétimo capítulo, onde o autor responde a seguinte questão: "como promover a cooperação?". No seu conjunto, esta resenha busca introduzir ao Direito Negocial algumas das contribuições de Axelrod para o estudo da cooperação sob o prisma da Teoria dos Jogos.

Palavras-Chave: Cooperação, Dilema do Prisioneiro, Robert Axelrod, Teoria dos Jogos.

Abstract: Robert Axelrod in his book "The Evolution of Cooperation", analyzes the development of cooperation in non-zero-sum games, more specifically, in the Prisoners' Dilemma. Moreover, his contributions are not restricted, solely, to mathematics and computer program tournaments because it can be applied to international relations, microbiology, and even law. Considering this books density, we will examine only chapter 7, where the author answers the following question: "how to promote cooperation? All in all, this review seeks to introduce to Business Law some of Axelrod's contributions to the study of cooperation within the context of Game Theory.

Keywords: Cooperation, Prisoners’ Dilemma, Robert Axelrod, Game Theory.

A obra "The Evolution of Cooperation" do cientista político Robert Axelrod examina a evolução e desenvolvimento da cooperação em jogos de soma não zero, como o Dilema do Prisioneiro. Em si, a pesquisa pode ser aplicada não somente em áreas de conhecimento como a matemática e ciência da computação, mas em outras como a microbiologia, relações internacionais e até Direito. No Direito Negocial, observa-se de especial importância, uma vez que negócios jurídicos dependem de cooperação para que contratos, testamentos etc. sejam executados conforme a vontade da(s) parte(s). Se analisado por um prisma processual, o Código de Processo Civil de 2015 (CPC/2015) acolhe a cooperação como seu atual paradigma, considerando que a redação de seu art. $6^{\circ}$ estabelece o dever de cooperação entre sujeitos processuais. Tendo isso em vista, 
resenha-se o sétimo capítulo, "How to Promote Cooperation", do livro de Axelrod para demonstrar como a cooperação pode ser promovida nos mais variados ambientes e contextos históricos, sociais e econômicos.

O capítulo 7, que pode ser traduzido em "Como promover cooperação?” busca responder exatamente esta questão. $\mathrm{O}$ autor entende que a cooperação mútua é benéfica para os jogadores, uma vez que possibilita, no Dilema do Prisioneiro, receber pontuações mais altas e benéficas para ambos os jogadores. Como trata-se de um jogo de soma não zero, não possui como delimitador "ganhar" e "perder". Xadrez, por exemplo, configura um jogo de soma zero exatamente porque para um ganhar, o outro precisa perder. No Dilema do Prisioneiro, se todos cooperarem, todos podem ganhar, ou seja, com a cooperação, ninguém perde. Axelrod aponta que um dos fatores para incentivar a cooperação é aumentar a "sombra do futuro", pois a cooperação só consegue ser promovida se os jogadores acreditarem que esta escolha pode beneficiá-los no futuro próximo. Ou seja, se não houver possibilidades de reencontro entre os jogadores, estes não possuem incentivo para não cooperar, tendo em vista que no Dilema do Prisioneiro, não cooperar é mais benéfico considerando a interação individualizada. Quando há reiterados encontros, a melhor escolha para os jogadores seria a cooperação, porque só assim conseguiriam obter a melhor pontuação geral. Por isso, o autor declara que caso o ambiente não promova, naturalmente, a cooperação, é necessário arquitetá-lo para que assim o faça.

Um segundo fator para estimular a cooperação, é a modificação das recompensas de modo que cooperar, em dado contexto, compensaria mais do que a alternativa. Desta forma, afirma que o propósito das leis é estimular a cooperação para que a sociedade se beneficie disto, a exemplo do pagamento de tributos ou do cumprimento de contratos com terceiros. Analogicamente, se o Estado for passivo, ao não aplicar leis existentes ou permitir a aprovação de leis que não punem condutas contrárias a cooperação, a cooperação restará desincentivada, visto que que não haverá punição pela não cooperação. Assim, um Estado que é omisso em, por exemplo, punir a sonegação de impostos, estará, em essência, estimulando-a - o que prejudica diretamente o seu proveito pela sociedade. O mesmo é possível no estímulo para a cooperação, permitindo ao indivíduo que coopera usufruir de benefícios maiores por sua conduta. É possível, ainda, fomentar a cooperação pela socialização, ensinando as pessoas a se preocuparem com o bem-estar do outro, uma vez que uma sociedade repleta de pessoas com esta mentalidade terá mais facilidade para estimular o trabalho conjunto, de forma a beneficiar todos, assim, o autor entende que o altruísmo não se limita unicamente a biologia ou relações de afetividade, podendo ser desenvolvida em qualquer contexto mediante esta socialização.

Axelrod delimita a reciprocidade como um elemento central para a cooperação. Afirma que seguir a "regra de ouro" ou "regra áurea", que significa que cada um deve tratar o outro como gostaria de ser tratado, não é a melhor estratégia em face de terceiros que utilizam a não cooperação como regra inicial ou principal para suas ações. Neste caso, se o indivíduo sempre cooperar, enquanto o outro não cooperar, o primeiro sempre receberá a maior pena, enquanto o segundo sempre sairá livre no Dilema do Prisioneiro. Assim, a reciprocidade é a melhor estratégia, porque caso um jogador optar pela não cooperação, o movimento seguinte do outro deve refletir esta escolha. A reciprocidade não se aplica unicamente para jogos simulados, mas para todas as áreas da vida, especialmente, em ambiente sociais, onde podem existir pessoas que buscam tirar proveito alheio. Em face destes, a melhor estratégia seria retribuir a não cooperação. No entanto, o autor destaca que isso pode levar a ações sucessivas de não cooperação, o que acaba prejudicando o desempenho geral dos jogadores. Além disso, em um ambiente onde não existe autoridade central, esta resposta pode traduzir uma estratégia de "olho por olho" onde retribui-se a conduta anterior com o mesmo peso e medida. Já em um ambiente com uma autoridade central, como em um Estado, o peso da retribuição pode ser alterado. Por fim, a quinta e última maneira para desenvolver a cooperação é treinar os jogadores para lembrarem as estratégias utilizadas de outros 
jogadores em jogos anteriores. Isso possibilita um prognóstico das estratégias utilizadas. Desta forma, se o jogador notar que a outra parte é, predominantemente, cooperativa, com base em jogos anteriores, não faz sentido não ser cooperativo, uma vez que a melhor nota conjunta só consegue ser atingida se ambos cooperarem.

Em suma, o autor aponta para cinco caminhos para promover a cooperação, podendo ser aplicadas em vários contextos além de jogos ou torneiros simulados por programas de computador. Conforme a ordem apresentada por Axelrod são: (i) modificar o ambiente para possibilitar futuras interações entre jogadores; (ii) alterar retribuições ou recompensas; (iii) educar pessoas a se preocuparem com o outro; (iv) ensinar e estimular a prática da reciprocidade; (v) melhorar o reconhecimento de condutas e estratégias praticadas por outros jogadores. Posto isso, a obra contribui significativamente para entender os benefícios da cooperação e como desenvolvê-la de forma que todos possam lhe aproveitar, especialmente nas relações negociais.

Como citar: FARIA, Bruna. Chapter 7: How to promote cooperation. Em: AXELROD, Robert. The Evolution of Cooperation. Nova Iorque: Basic Books, 2006, p. 124-141. Scientia Iuris, Londrina, v. 25, n. 2, p. 208-210, jul. 2021. DOI: 10.5433/2178-8189.2018v22n2p208. ISSN: 2178-8189. 